\title{
Universal Oxidation for CBW Decontamination: L-Gel System Development and Deployment
}

E. Raber, R. McGuire, M. Hoffman, D. Shepley, T. Carlsen, P. Krauter and A. Alcaraz

\section{July 10, 2000}




\section{DISCLAIMER}

This document was prepared as an account of work sponsored by an agency of the United States Government. Neither the United States Government nor the University of California nor any of their employees, makes any warranty, express or implied, or assumes any legal liability or responsibility for the accuracy, completeness, or usefulness of any information, apparatus, product, or process disclosed, or represents that its use would not infringe privately owned rights. Reference herein to any specific commercial product, process, or service by trade name, trademark, manufacturer, or otherwise, does not necessarily constitute or imply its endorsement, recommendation, or favoring by the United States Government or the University of California. The views and opinions of authors expressed herein do not necessarily state or reflect those of the United States Government or the University of California, and shall not be used for advertising or product endorsement purposes.

Work performed under the auspices of the U. S. Department of Energy by the University of California Lawrence Livermore National Laboratory under Contract W-7405-Eng-48.

This report has been reproduced directly from the best available copy.

Available to DOE and DOE contractors from the

Office of Scientific and Technical Information

P.O. Box 62, Oak Ridge, TN 37831

Prices available from (423) 576-8401

http://apollo.osti.gov/bridge/

Available to the public from the National Technical Information Service

U.S. Department of Commerce 5285 Port Royal Rd., Springfield, VA 22161 http://www.ntis.gov/

OR

Lawrence Livermore National Laboratory Technical Information Department's Digital Library http://www.llnl.gov/tid/Library.html 


\section{Universal Oxidation for CBW Decontamination: L-Gel System Development and Deployment}

\section{Ellen Raber}

Co-Investigators:

Ray McGuire, Mark Hoffman, Don Shepley, Tina Carlsen, Paula Krauter, Armando Alcaraz, Lawrence Livermore National Laboratory

July 10, 2000 



\section{Universal Oxidation for CBW Decontamination: L-Gel System Development and Deployment}

Ellen Raber

Lawrence Livermore National Laboratory (925) 423-3985

raber1@1lnl.gov

Co-Investigators: : Ray McGuire, Mark Hoffman, Don Shepley, Tina Carlsen, Paula Krauter, Armando Alcaraz, Lawrence Livermore National Laboratory

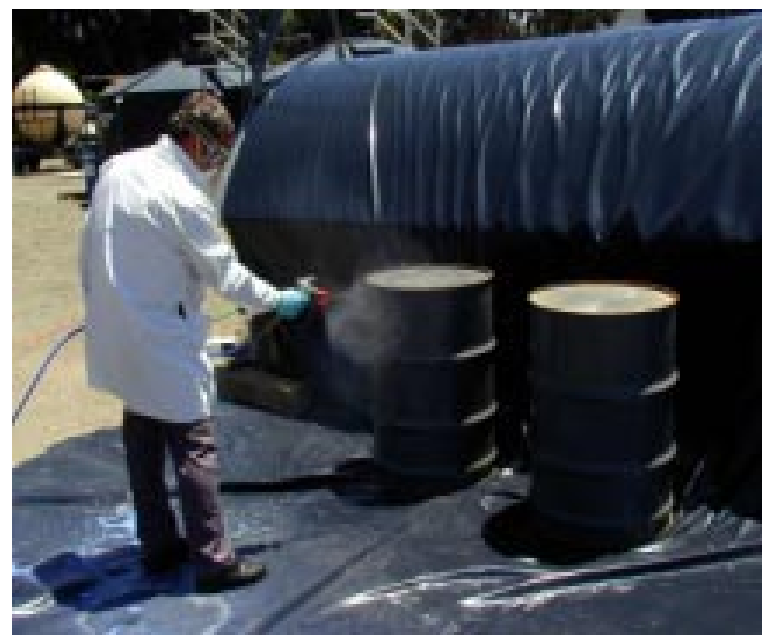

\section{Objectives}

L-Gel application exercises at LLNL

The optimum goal of this study is to develop a single decontamination system for chemical and biological agents which is non-toxic, non-corrosive, and easily deployable. The specific objective of this work was to evaluate oxidizer systems as reagents for detoxification and/or degradation to non-toxic environmentally acceptable components rather than necessitate complete destruction. Detoxification requires less reagent material than total oxidation, thereby reducing the logistic burden for a decontamination team.

One of the goals is to develop decontamination systems for use by first responders as well as more complete systems to be used by specialized decontamination teams. Therefore, the overall project goal is to develop better decontamination methods that can be quickly implemented by these organizations. This includes early demonstrations and field work with companies or other government agencies who can identify implementation concerns and needs. The approach taken in this work is somewhat different than the standard military approach to decontamination. In a battlefield scenario, it is critical to decontaminate to a useful level in a very short time so the soldiers can continue their mission. In a domestic, urban scenario, time is of less consequence but collateral damage and re-certification (public perception and stakeholder acceptance) are of much greater importance.

Since we wanted to maximize the contact time between the decontaminating reagent and the contaminant agent, we selected gelled reagents as the primary carrier material. Gels have the additional advantage of adhering to vertical or horizontal surfaces such as walls and ceilings. Lawrence Livermore National Laboratory, over a period of twenty years from the late 1960s to the late 1980s, developed a series of extrudable high explosives based on the gelling of polar energetic liquids. While never going into production, this development served as an experience base for formulation, characterization and dispersal system design and fabrication. It was a logical step, therefore, to adapt this work to the gelling of aqueous oxidizers for candidate BW/CW decontaminants. 
During this last year LLNL has focused on the development of the L-Gel oxidizer system and has primarily been involved in $\mathrm{CW}$ and $\mathrm{BW}$ laboratory and field testing which has helped to refine and improve the previous formulation. Additionally, we have evaluated the feasibility of developing an aerosolized system based on the L-Gel formulation. The results of these studies will be discussed.

\section{$\underline{\text { Recent Progress }}$}

Previous experimental testing at LLNL has shown that RO• (peroxyl) oxidizers are the most effective for complete $\mathrm{CW}$ and $\mathrm{BW}$ decontamination. The primary decontamination system now under development at LLNL is based on the commercial oxidizer "Oxone" manufactured by DuPont. The active ingredient is potassium peroxymonosulfate. Previous research at Edgewood Chemical and Biological Center (ECBC) had demonstrated the effectiveness of aqueous oxone in decomposing both VX and Mustard-type agents. While decomposition of " $G$ " agents occurred, the reaction was very slow because of the low $\mathrm{pH}$ of the system. The acidic $\mathrm{pH}$ is necessary, however, in the case of VX, where it leads to the protonation of the amino nitrogen and enhances the oxidation of the sulfur. Once the sulfur is oxidized, the P-S bond is easily and irreversibly hydrolyzed, detoxifying the "V" agent. A similar oxidation of the sulfur in Mustard facilitates the hydrolysis of the $\mathrm{C}-\mathrm{Cl}$ bonds. These hydrolysis mechanisms have been studied and verified in the laboratory.

LLNL has incorporated a fumed silica gelling agent into the oxone solution. The fumed silica has the added property of catalyzing the hydrolysis of " $G$ " agents, making broad spectrum decontamination feasible. Presently, LLNL has developed and successfully tested two L-Gel formulations. These current gel formulations consist of $\sim 0.5$ to $1 \mathrm{~N}$ oxone reagent solution with $12-20 \%$ Cab-o-sil EH-5 fumed silica and various additives depending on whether the formulation will be used on thickened CW agents. These types of gels have the advantage of being compatible with strong oxidizing agents as well as an added advantage of maximizing contact time due to their thixotropic nature. This ability of certain gels to liquefy when stirred or shaken and return to the "solidified" state upon standing enhances material handling and application. In particular, these gels have an advantage of adhering to vertical and the undersides of horizontal surfaces such as ceilings and walls. The viscosity of the system can be varied depending on the application. Activities this year involved optimization of gel mixing and dispensing with commercially available equipment including documentation of operating procedures for field testing.

The L-Gel systems are pre-gelled/pre-mixed and ready to use as delivered. If unopened, the shelf-life is expected to be in excess of one year, although long-term testing is still underway. This allows the gel to be shipped and stored as a semi-solid material which is easily re-liquefied (by vigorous hand shaking or use of a power stirrer) and then sprayed using an airless paint sprayer. The final formulation is relatively non-corrosive $(\mathrm{pH} \sim 4$, similar to vinegar or lemon juice) and EPA testing on the residual materials from surrogate experiments shows residues to be non hazardous. For indoor use, after the gel is dry (1-6 hrs), it can simply be vacuumed up and discarded. For outdoor usage, no cleanup is required.

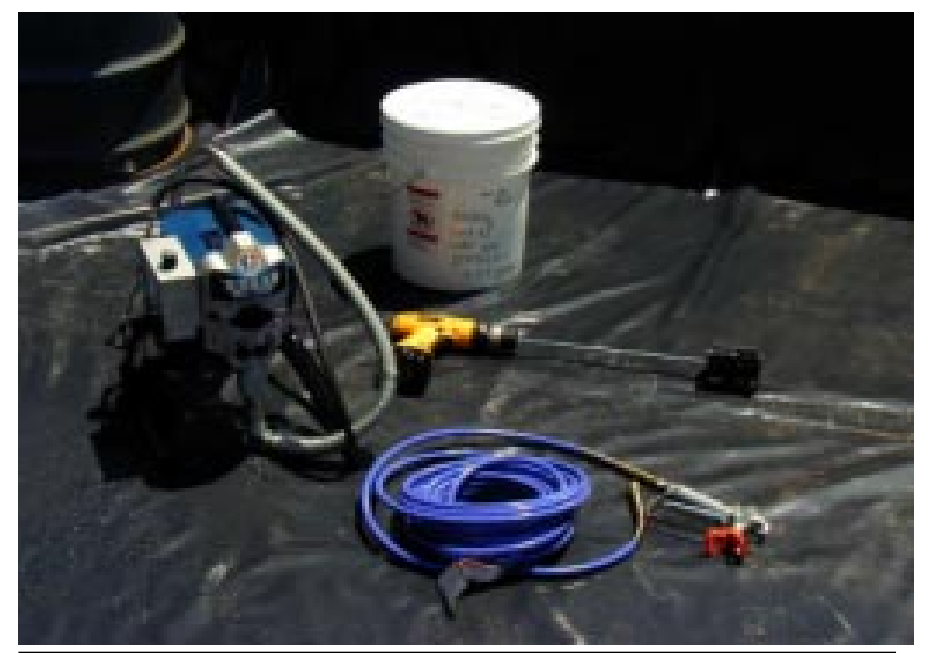

Equipment for L-Gel application is commercially available 
The current L-Gel system (L-115) has been tested on a variety of different materials as would be expected in an actual decontamination scenario (i.e., fiberglass, varnished wood, painted steel (acrylic paint), and indoor/outdoor carpet, concrete, asphalt). The results of these initial tests using both surrogate and real agents showed the L-Gel formulation to be effective for both $\mathrm{CW}$ and $\mathrm{BW}$ agents. Details of these tests have been previously presented. Additional CW and BW agent laboratory and field testing has continued to verify the effectiveness of the L-Gel decontamination system. 
In December 1999, LLNL participated in BW field tests conducted by the Soldiers Biological and Chemical Command at the US Army Dugway Proving Ground/West Desert Test Center. Six selected materials were contaminated with $\sim 1 \times 10^{9} / \mathrm{m}^{2} B$. globigii spores and evaluated. The L-Gel performed very well in these tests. The number of live spores on test panels were reduced by an average of $99.988 \%$ through the application of the L-Gel.

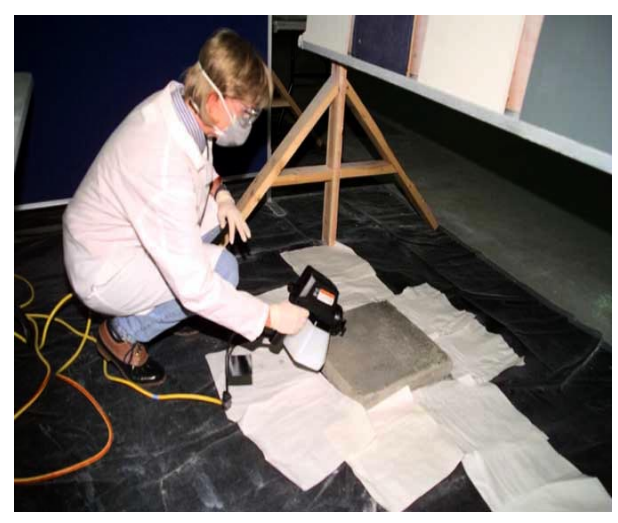

Additional follow-on testing this year at Porton Down with thickened CW agents was not as successful.

L-Gel panel application of SBCOM Dugway BW trials Specifically, a limitation was identified concerning the inability of the L-Gel to penetrate surfaces with heavily coated paint/varnish. Therefore, we have developed a second formulation (L-Gel 200) which contains a co-solvent mixture which effectively promotes solution_and oxidation for thickened agents. Surrogate laboratory experiments have been successful as well as additional testing in the Czech Republic. This formulation is currently undergoing real CW agent field testing as part of the RestOps JCFT cycle for this July-October 2000 at the West Desert Test Center, Dugway Proving Ground.

The L-Gel effort has been recently expanded to develop a "solid-water" aerosolized form of the liquid decontaminate capable of delivering $80-95 \% 1 \mathrm{~N}$ oxone solution directly to chemical agent for use in ventilation ductwork or other confined spaces. This is based on a concept recently developed by DeGussa Corporation and patented as "Dry Water." Functionalized silanes are reacted with hydrophilic $\mathrm{SiO}_{2}$ particles to produce nanoparticles of hydrophobic silica. The hydrophobic silica then is used to coat aerosolized water droplet forming a powder containing 97-93\% water. Preliminary experiments have shown that we can make a similar aerosol material with $1 \mathrm{~N}$ oxone which was successful in decontaminating CEES in 30 minutes. We are continuing to develop these and/or special hydrophobic nanoparticles for coating aerosolized oxidizer solutions. If the powder interface can be tuned to allow the encapsulated oxone to break down when it comes in contact with liquid agent, duct work and conduit could be detoxified relatively easily and directly.

\section{Future Outlook}

- Technology transfer and licensing agreements have been initiated and it is hoped to have a commercial partner identified by September 2000.

- LLNL plans to continue participation in the three CW RestOps JCFT trials at US Army Dugway Proving Ground/West Desert Test Center scheduled for late summer/earlier fall.

- LLNL plans to participate in the BW Room Decontamination exercise coordinated by the Soldiers Biological and Chemical Command at the US Army Dugway Proving Ground/West Desert Test Center.

- Future planning and participation in RestOps South Korean Exercise is planned.

- We plan to continue evaluations of L-Gel "Solid-water" aerosols for ventilation decontamination. 


\section{Experiments/Field Testing}

\section{CW Laboratory Testing, Porton Down, October 1999}

L-Gel was tested against thickened GD and thickened Mustard (HD) on painted panels. With a reaction time of 30 minutes, the L-Gel destroyed from $40 \%$ to $65 \%$ of the thickened agent. Based on these results, it was decided to modify the L-Gel formulation to add a co-solvent for situations involving thickened agents.

\section{DOD Fixed Site Decontamination Testing, November 1999}

The L-Gel was tested at Edgewood Chemical Biological Center (ECBC) in a variety of tests involving agents on painted surfaces. Final results have not yet been published. However, L-Gel was shown to be effective in preliminary kinetics testing. The unofficial final results were considered in selecting L-Gel for further testing as part of the RestOps chemical field trials.

\section{Dugway Proving Ground BW Field Test, December 1999}

The test objectives were to (1) develop optimal techniques for biological warfare agent stimulant contamination of six type of material surfaces, (2) develop techniques for sampling/recovery of BWA stimulant contamination of materials surfaces, and (3) compare the ability of several decontamination materials to inactivate a BWA stimulant. As stated above, the number of live spores on test panels were reduced by an average of $99.988 \%$ through the application of the L-Gel.

\section{RestOps JCFT, July-October 2000 at the West Desert Test Center, Dugway Proving Ground.}

Three CW agent tests are scheduled for this summer. This includes laboratory testing with real agents on panels, combined CW agent and surrogate laboratory testing on panels, and an equipment field decontamination test with surrogate materials. LLNL has sent 5 gallons of L-gel materials and the associated delivery equipment. We have participated in personnel training exercises.

\section{$\underline{\text { Citations }}$}

- "Chemical and Biological Decontamination for Civilian Facilities," Ellen Raber, Decon 2000 Homeland Defense Symposium Proceedings, Santa Monica, CA, 8 February 2000. (in press)

- "Decontamination Issues for Chemical and Biological Warfare: "How Clean is Clean Enough?," Ellen Raber, Decon 2000 Homeland Defense Symposium Proceedings, Santa Monica, CA, 8 February 2000. (in press)

- "Universal Oxidation for CBW Decontamination: L-Gel System Development and Deployment" Authors: Ellen Raber, Ray McGuire; Co-Investigators: Mark Hoffman, Armando Alcaraz, Don Shepley, Jeff Elliott, Paula Krauter, Emilio Garcia, 16 December 1999, UCRL-ID-137426

- “CBW Decontamination Agent Development," Paula Krauter and Emilio Garcia, Decontamination Conference 2000 Symposium Proceedings, Salt Lake City, UT, 23 May 2000 . 